\title{
Baseline Assessment in the Elementary Mathematics Classroom: Should it be Optional or Mandatory for Teaching and Learning?
}

\author{
Mamsi Ethe Khuzwayo \\ Cape Peninsula University of technology, Cape Town in Mowbray, South Africa \\ http://orcid.org/0000-0002-4084-8773 \\ Herbert Bhekumusa Khuzwayo \\ University of the Western Cape, Cape Town in Belville, South Africa \\ http://orcid.org/0000-0002-6732-1787
}

\begin{abstract}
Too few mathematics teachers have the expertise to apply baseline assessment for differentiated learning in mathematics classes. This empirical study was conducted in a focus group of sixty learners and three teachers in a grade four mathematics class. It proved that teachers of mathematics in elementary grades could profitably learn to conduct baseline assessments; developing activities to benchmark learners' abilities and learning needs. The exploratory research design was utilized to set up the general sample and the focus group, and mixed research methods; qualitative and quantitative instruments to collect data and analyzing data. The records of scores obtained by learners from the assessment activities and the interviews with teachers were the main sources of data. Data analysis followed quantitative procedures and presented in figures and categorized them in frequency distribution tables. Findings highlighted that learners can reach their optimal levels in learning mathematics in a free and flexible environment. This paper concludes that the lack of knowledge about how to conduct baseline and its value is one of the attributes of the high failure rate of children in the middle class. This article recommends the consideration of baseline assessment to be an essential aspect of a continuous professional development program for mathematics teachers.
\end{abstract}

Keywords: Assessment; Baseline; Differentiated; Learning; Styles

\section{Introduction}

The democratic education dispensation in South Africa is in keeping with the international trend to acknowledge diverse learners' needs. White paper 6 (DBE, 2011) was promulgated by the Department of Education to enforce the principle of inclusivity in the teaching and learning programs in mainstream classrooms. 
Research highlights, however, that implementing principles of inclusivity in curriculum delivery at the classroom level is a challenge to many teachers (Donohue \& Bornman, 2014; Hazel, Spencer \& Robert, 2019). An in-depth review of the mathematics curriculum innovation called: Curriculum and Assessment Policy Statement called, (CAPS) informed this work and shows gaps between the curriculum blueprint and multi-level teaching and learning. Mathematics teachers are expected to bridge these gaps for multi-level and differentiated learning to take place in mathematics classes.

According to the principles stipulated in the White Paper 6; mathematics teachers are expected to perform the following pedagogical roles; design learning activities that are sensitive to the varying needs of both the subject and the learners, create a supportive and empowering environment for the learners, and integrate assessment between teaching and learning (Department of Basic Education, 2011; 2019). Rhetorically, the attributes and the roles for the competent teacher related to inclusive education system indicate that: first, educators must have an understanding of the; purposes, methods, and effects of assessment and be able to provide helpful feedback to learners. Second, design and manage both formative and summative assessments in ways that are appropriate to the level and purpose of the learning. Third, understand how to interpret and use assessment results to feed into processes for the improvement of learning programs. Fourth, keep detailed and diagnostic records of assessment results (Department of Higher Education and Training, 2019, p.58).

The narrative about inclusivity and diversity often centers on the issues of socioeconomic background, physical challenges, and cognitive abilities (Tomlinson, 2013; Aghamdi, Jitendra \& Lein, 2019). This article relates issues of the poor performance of learners in mathematics too, poor preparation of teachers in the subject content knowledge and pedagogy, to consider diverse learning needs in mathematics classes. The perspective, which we have adopted in this work emphasizes that mathematics classrooms are composed of multiple groups of learners; some do not have difficulties with mathematical knowledge and skills but who experience challenges with learning styles that are not aligned with their cognitive structures.

\section{Background}

The Department of Basic Education (DBE) produced curriculum guidelines for teachers and school-based curriculum specialist and district-based subject advisors yet research points to a deteriorating performance among learners in grade 3 and grade 6 (Department of Basic Education, 2011; Venkat \& Spaull, 2015; Department of Basic Education, 2019). Intermediate (middle grades) learners are often unable to perform necessary, elementary cognitive numerical and mathematical skills (Mullis, Martin \& Hooper, 2017). Venkat and Spaull (2015, p. 127) revealed the results of the analysis of data gathered by, Trends in International Mathematics and Science Study (TIMSS) that, 61\% of South African Grade 5 learners could not do basic mathematics, for example, performing of addition and subtraction of the whole numbers, multiplication by one-digit numbers, and cannot solve simple word problems. 
This work recognizes the findings reporting the inadequacy of the initiative of the DBE to increase the performance of learners in mathematics at elementary grades. Documents produced by the National Department of Education explain the initiative called 'The Foundations of Learning Campaign', a project introduced by the Department of Education in 2008 to increase the performance of all primary school learners in Numeracy/Mathematics to no less than $50 \%$. The Foundations for Learning Campaign culminated in a national evaluation at the end of 2011 to assess the Literacy (Languages) and Numeracy (Mathematics) levels of grade three and six learners in South Africa to determine the impact of the campaign (Department of Basic Education, 2019).

The analysis of the results of the Foundations of Learning Campaign revealed that the campaign did not focus on the alternative pedagogical approaches; instead teachers were merely given material. Research continued to point at the inconsistencies in the pedagogical approaches, emanating from the unaligned and uninformed practices in mathematics classrooms nationally (Hazell, Spencer \& Robert, 2019; Henning et al. (2019). In the same, vein (Graven, 2014) agreed that the campaign did not yield positive results to implement alternative pedagogical approaches for teaching and learning of mathematics in elementary classes. Amidst, the challenges that threatened the effective implementation of the campaign and other innovations to improve the teaching and learning of mathematics, the main issue of concern is the incompetency of teachers to address multi-level abilities and diverse learning difficulties experienced by individual learners in classrooms (Reddy, 2006; Department of Basic Education, 2019; Fleisch, 2008; Schollar, 2008). Research shows that the challenge of overcrowded classrooms, lack of resources, and rapid changes in the alignment of the curriculum are the attributes of a high rate of failure in mathematics (Tomlinson, 2020; Blomeke, Kaiser \& Koning, 2020). Spaull and Kotze (2015), however, argue that the issues of the language comprise the root course of the high failure rate in mathematics classes in South Africa. Henning et al. (2019) in the same vein write that there is a great need for the use of home language to teaching and learning other than the second language which has a profoundly negative impact upon the acquisition of mathematical concepts in elementary classes.

Concerns are mounting about the poor performance of learners in mathematics. The problem identified after the critical synthesis of the findings and recommendations is that, there seems to be little information said in the literature regarding accommodating diverse learning styles in the specialized mathematics pedagogical content knowledge to support the implementation of inclusive policy in classrooms in South Africa. The curriculum change policy indicates that the envisaged teacher should:(i) demonstrate an ability to prepare and develop activities that complement diverse learning styles in the classroom, (ii) be a subject and phase specialist and, be able to conduct assessments.

The question that this study sought to address was: Is baseline assessment significant to benchmark diverse learning needs in the elementary mathematics classes? 
The problem statement for the study was, to explore the approaches applied by learners to acquire mathematics content knowledge; concepts, cognitive skills, and application in the multiplication activities designed by teachers.

\section{Literature Review}

Relevant literature posits that the perspective of assessment held by the National Department was that of integrating assessment to teaching and learning. The rationale to integrate, to monitor learning progress was to provide necessary feedback to individual learners in the process of teaching and learning of mathematics content knowledge (Department of Basic Education, 2011, 2019). The advocacy document on assessment policy pioneered a view of formative and developmental assessment and emphasized continuous assessment where a variety of techniques and methods could be applied to collect or gather evidence on learners' performance (Aghamdi, Jitendra \& Lein, 2019; Andrade \& Brookhart, 2019; Department of Basic Education, 2019). Teachers of mathematics are expected to conceptualize in their practices of pedagogy is that of a continuum that serves to highlight the learning needs of individual learners concerning the goals and objectives of the mathematics curriculum. The practice of continuous assessment in South African schools stresses three purposes of assessment (baseline, formative and summative) in the learning environment. The most critical purpose of assessment is to identify gaps in learners' previous knowledge and identify learners' levels of cognitive and affective abilities. According to the guidelines of the Department; for the evaluation to serve the baseline purpose, teachers are expected to design activities which benchmark levels of skills, proficiency, expertise, existing knowledge gaps and misconceptions at the beginning of the new grade, and before embarking on the new theme of learning context (Henning et al., 2019; Bondie, Dahnke \& Zusho, 2019).

In the same narrative, Tiymms (2013), and Tomlinson (2020) highlights the results of the baseline assessment, which provides the teacher with information about learners' abilities and knowledge gaps. Based on that information, the teacher can structure the learning content, select and align strategies of teaching and learning with each learner, or a group of learners' learning needs. A synthesis of policy documents for teacher qualifications in South Africa shows that pre-service and in-service programs should equip teachers with competences in assessment, program designers, and subject/phase specialists (Department of Basic Education, 2019, Department of higher education, 2019). Semana and Santos (2018) posit that the proposed new approaches to assessment and teaching depend on the eagerness and commitment of teachers to track the progress made by individual learners in the classroom. Proponents of baseline assessment hold that assessment tasks should provide adequate opportunities for learners to express their individuality. Research suggests that in a group of mixed abilities and learning styles, teachers should first have mastered the knowledge and skills for diagnosing learners' difficulties along with styles of learning before making judgments about the capabilities of learners in the mathematics class (Tomlinson \& Tonya, 2013; Sausa \& Tomlinson, 2011; Wright, Martland \& Stafford, 2006). For teachers to be competent assessors, they are 
expected to use these opportunities to develop learning profiles for individual learners which points to the conditions under, which some learners learn best. The information gathered during the assessment enables teachers to create and adjust subject content knowledge and contexts of learning concepts and skills to suit learners' interests, experiences, and abilities (Baubeng, Atingane \& Amoako, 2019; Goulet-Lyle, Voyer \& Wershaffel, 2019; Amoako, Brembong \& Bartey, 2019; Kim, 2019; Nguare, Hungi \& Mutisya, 2018).

\section{Conceptualized framework for baseline assessment}

Advocates of baseline assessment in the context of education assert that the principal reason for a baseline in teaching and learning is to get to know children at the entry-level of a new phase of schooling (Tiymms, 2013; Nguare, Hungi \& Matisya, 2018; Tomlinson, 2020). The purpose of baseline assessment, according to the Department of Basic Education (2019) is to help teachers to develop learning activities that are inclusive of the differentiated learning styles, and to identify the special needs of children at an early stage, so that the remediation program can be put in place. Tomlinson and Moon (2013, p. 182) agree that baseline assessment is supposed to be at the heart of curriculum innovations since it establishes a baseline for gauging future progress, not only for individual learners but for the entire class. According to some researchers, baseline assessment may be organized in various forms which, could be: a test written by all learners in a class at the beginning of the learning program, which could be carried out in 20 to 25 minutes. Alternatively, baseline assessment could be carried out through easily manageable activities that are carefully developed to measure subjective and objectives values and indicators necessary for future development and progress (Henning et al., 2019; Kim, 2019; Nguare, Hungi \& Mutisya, 2018).

\section{Theoretical framework}

The theoretical framework for the research project was established from the principles asserted in the theory of multiple intelligences, Multi-levels, and differentiated learning (Tomlinson, 2020; Bondie, Dahnke \& Zusho; 2019; Tomlinson, 2013; Davis, Christodoulou, Seider \& Gardner, 2011). These theories explain the formation or composition of a classroom as a community of individuals who come from different socio-cultural and economic backgrounds, and individuals who have bits of intelligence, experiences, and interests are nurtured.

Dryden and Vos (2005, p.146), indicate that bits of intelligence are certain traits and propensities for learning specifics skills that everyone possesses at birth. The development of the potential bits of bits of intelligence in learning is determined by how they are nurtured to become sets of skills and abilities. According to Sternberg (1985) in Dryden and Vos (2005, p. 146), intelligence takes three forms: analytical, creative, and practical. Gestalt Psychologists uphold a similar theoretical view about the development of cognitive and affective skills: they point out the importance of interest, experience, configuration, patterns in the stimuli, and relations (Bondie, Dahnke \& Zusho, 2019). 
Multi-level and multi-intelligence theories advert to the critical principles to be reckoned with when identifying traits and propensities of learners: (i) flexibility in the organizations of learning material (ii) reading and comprehension of the language of teaching and learning and (iii) familiarity with the context of in which learning of content knowledge takes place (Wright, Martland \& Stafford, 2006).

\section{Methodology and Research Design}

This study employed a mixed-method research paradigm drawing from the ideas and views of Creswell and Creswell (2018, p.265) quantitative and qualitative methods allow the researcher to gather numerical and narrative data from the same sample. According to Henning, Van Rensberg \& Smit (2013, p.35) qualitative, the methods of data collection can be personal narratives or participatory observation. The phenomenological case design was appropriate for the selection of participants, managing the phases of qualitative data collection and data analysis.

This study had two sources of data gathered through the quantitative and qualitative procedures, the learners' scores comprise quantitative and narrations of the qualitative data from interviews.

\section{Sampling}

A purposive sampling strategy was used to select participants in the sample and focus groups. The purpose was to gather reliable and valid data upon which findings could address the research problem and the purpose of the study. Grade 4 teachers from each of the three schools selected twenty mathematics learner books, and the total number of books analyzed in this study was 60 . The rationale for choosing class four learners in this sample is that class four is an entry grade in the middle schooling or intermediate phase.

\section{Instruments}

Tymms (2013, p.233) suggests three types of instruments for gathering data: employing, observation schedule and assessment activities for quantitative data and in-depth interviews for qualitative data. Observations alone, however, cannot provide objective comparative data, nor can they probe indicators of individual learners' learning styles (Tymms, 2013). Observations and assessment activities were used in this study to complement subjective and objective data and to ensure that good productive validity was monitored. In the same vein, Bondie et al., (2019) state that in mathematical learning, particularly, observation may not reveal indicators, hence carefully chosen activities are required to supplement data. In-depth interviews were conducted after the collection of data from the learner workbook, and the results of baseline assessment activities were analyzed.

\section{Data collection procedures}

Ethics for this study were considered, and that entailed permission from gatekeepers, the Kwazulu-Natal Department of Education, and school principals. The consent of the participants was given in writing. Anonymity and confidentiality of all participants were assured. 
First stage data collection: Meetings were arranged with three grade four mathematics teachers in three different primary schools in a selected township in the Northern KwaZulu-Natal province, respectively. Schools were visited on different days during the second term. The topic which was chosen was on multiplication according to the school's work schedules. It was selected because it was part of the work which was covered during the term in which the study was conducted. Schools A, B, and C were using the same workbook. Learners completed the same activities in the grade 4 learners' book as prescribed by the Department of Basic Education.

\section{Procedures of data analysis}

The quantitative data was coded, categorized, and organized according to the trends and patterns manifested. Trends from the coded data were identified through the observed frequency showing similarities from each category. The categories focused on the descriptions of techniques from the Multiple Intelligences, and they were of assistance for aligning learners' differentiated approaches to solving problem applying mathematical operations in different contexts of the activities. The pie chart and tables were generated to present the summaries of data. Qualitative data was also coded and classified under categories and thereafter patterns of thought manifested were organized into themes.

\section{Data gathered from learners' Mathematics learner books.}

The first set of data was gathered from the analysis of learners' performance in three multiplication activities. Recorded data were classified under the categories in the pie chart below, indicating difficulties experienced by learners with the multiplication activities in grade 4 learner books.

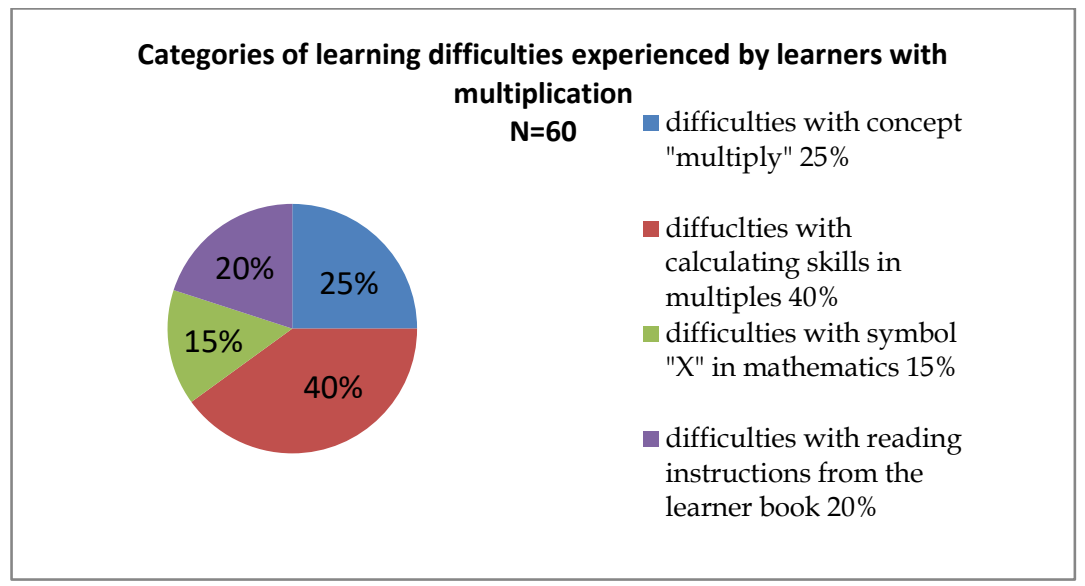

Figure 1: the pie chart showing the types of difficulties recorded from learners' performance in the multiplication activities.

Data gathered from baseline assessment activities.

The second phase of data collection focused upon learner performance in learning activities designed by teachers under the supervision of the researcher. 
The researcher and teachers were guided by three critical principles recommended in the Department of Basic Education (2019), Tomlinson (2020), and Bondie et al. (2019) where they developed and organized activities on worksheets: flexibility in the organizations of learning material, reading, and comprehension of the language of teaching and learning and familiarity with the context of Education. Learners were allowed to choose worksheets which they liked the most as long as they had the groupings of two and four. Below is the set of activities developed per differentiated learning styles for grade four learners, respectively.

The learning outcome for the activities: by the end of the learning activities, learners should be able to:

Differentiate between continuous addition and multiplication, count items in groupings, and to understand the concept of times, multiples through repeated counting.

Assessment Criteria or expected performed knowledge and skills from the activities were to; (i) apply the concept multiple as groupings (ii) Substitute items with symbols Repeating counting of 1 grouping in the context of times to develop tables of 2 and 4 on their own

Instructions:

Cut a picture from the worksheet and paste it on the sheet of paper provided and write two on top

Next to the margin write numbers 1,2,3,4,5,6,7

Count any grouping of two you see on the picture or objects you have chosen using the numbers $1,2,3-7$

Count any grouping of four you see on your picture or items using the numbers $1,2,3-7$

Visual-spatial learners: used objects to count in multiples of 2 and 4 . They scored the groupings on the one object repeatedly until they completed developing their tables. According to Davis et al. (2011), the visual-spatial learning style is characterized by an interest in working with real objects and pictures or photographs. The physical object e.g., counters and pictures, as well as drawings, were provided.

For example:

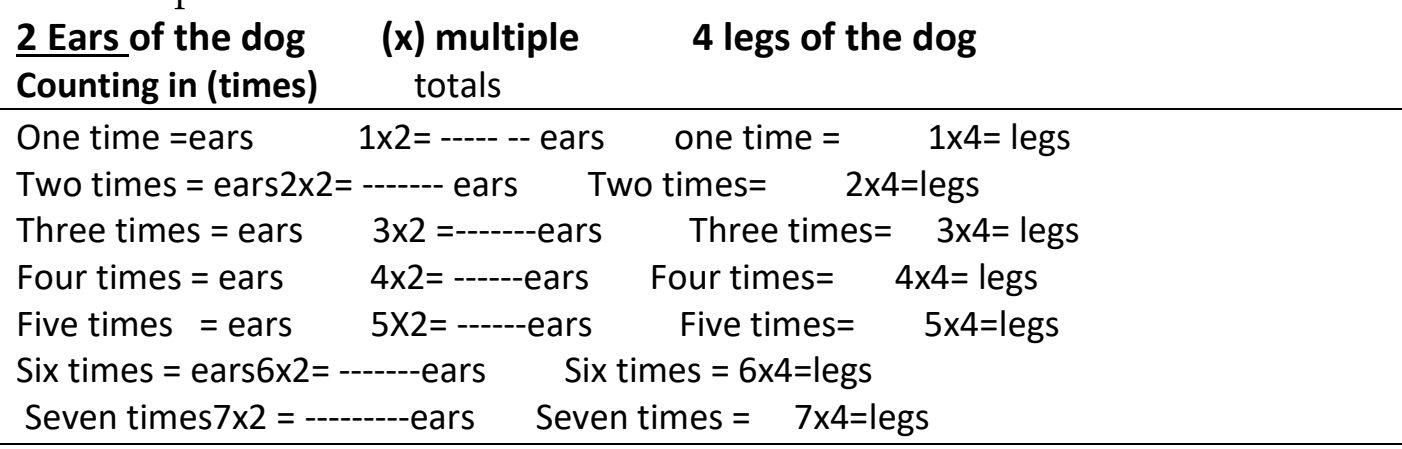


Bodily-Kinesthetic Learners: used baking pans and cookies to develop their tables of the multiples of 2's and 4's. Davis et al. (2011) describes bodilykinesthetic learning styles, to be physical movements. Enjoy creating things with his or her hands, remember by doing, rather than hearing or seeing.

The game was about sorting cupcakes into boxes. Sorting began with

One box of 2cupcakes, $1 \times 2=$

Two boxes of 2 cupcakes $2 \times 2=$

Three boxes of 2cupcakes $3 \times 2=$

Four boxes of 2 cupcakes $4 \times 2=$

Five boxes of 2 cupcakes $5 \times 2=$

Six boxes of 2 cupcakes $6 \times 2=$

Seven boxes of 2 cupcakes $7 \times 2=$

One box of 4 cupcakes $\quad 1 \times 4=$------cupcakes

Two boxes of 4 cupcakes $2 \times 4=------$ cupcakes

Three boxes of 4 cupcakes $3 \times 4=$------ cupcakes

Four boxes of 4 cupcakes $4 \times 4=$--------cupcakes

Five boxes of 4 cupcakes $5 \times 4=$--------cupcakes

Six boxes of 4 cupcakes $6 \times 4=$------- cupcakes

Seven boxes of 4 cupcakes $7 \times 4=-------$ cupcakes

Verbal Linguistic and Interpersonal learners were allowed to solve problems by reading story sums, pictures, and drawing they have created. Davis, Christodoulou, Seider \& Gardner (2011) asserted that the following interests and capabilities characterize the verbal-linguistic style of learning: Interpret pictures, graphs, and charts well; enjoy drawing, painting, and the visual arts, as well as recognizing patterns easily.

The data gathered through observation of learners' patterns of behavior and identified traits and propensities of learners demonstrated by individual learners during the learning activities, were classified under trends using Davis, Christodoulou, Seider \& Gardner (2011) descriptions of visual-spatial learning styles, verbal-linguistic learning style, interpersonal and body kinesthetic learning styles in the multiple intelligences theory.

The summary of data on the bar graph indicates the frequency of learners in the sample of 60 learners from three schools under each of the three learning styles, respectively. 


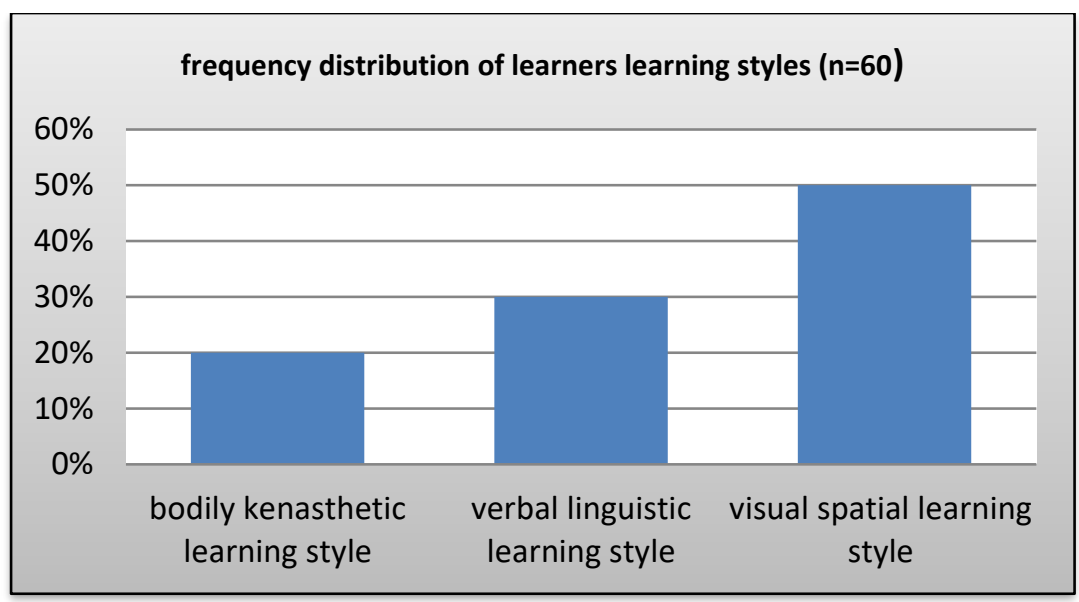

Figure 2: The bar chart shows the frequency distribution of behavioral patterns indicating learning styles identified from the combined group of grade four learners in the sample.

Data gathered concerning the expected performance stated in the performed goals or standards of the learning outcome.

The data gathered through analytic rubrics comprised a rating of the performance of individual learners against performance objectives (criteria and the learning outcomes). The objectives or criteria set the expected achievement of learners in the mastery of subject content knowledge, cognitive skills, and practical or applications.

The summary of raw scores obtained by learners under each category was classified in table 1 below. The data recorded during the learning and assessments were classified under each type of event. Individual Learners' learning styles were identified from the scores they obtained from each activity. The Performance was analyzed to understanding the class composition in terms of learning techniques

Table 1: shows the analysis of the feedback to the performance of diverse learning styles on each criterion, respectively.

\section{Number of entries 60}

$(\mathrm{N}=60)$

\section{Analytic assessment rubrics with descriptors}

Achieved (A): (abilities to understand the concepts of groupings and multiples in the context of time/s (first time, the second time, etc.), are demonstrated. The skill of identifying clusters counting, and calculating accurately are performed. Abilities two substitute words with numerical symbols in performing calculations following instructions were displayed.

Partial achieved (PA): abilities to understand concepts of clusters and multiples have partially improved; however, more practice is required. The skills of identifying groupings, counting, and calculation are still essential, and more training is essential. Guided reading to comprehend instructions is necessary. The abilities to develop a table of 2 and 4 have been mastered.

Not Achieved (NA): (abilities to understand the concepts of grouping and multiples 


\begin{tabular}{llll}
\hline & concept of 'multiply' & $\begin{array}{l}\text { skills of counting and } \\
\text { calculations }\end{array}$ & $\begin{array}{l}\text { substitution } \\
\text { with symbols }\end{array}$ \\
$\begin{array}{l}\text { Verbal- } \\
\text { linguistic \& } \\
\text { interpersonal } \\
\text { Bodily- } \\
\text { Kinesthetic }\end{array}$ & achieved & achieved & partial achieved \\
$\begin{array}{l}\text { Visual-spatial } \\
\text { achieved }\end{array}$ & partial achieved & achieved \\
\hline
\end{tabular}

Data Gathered from In-depth Interviews with three Teachers of 25 learners.

The following three questions were asked to three teachers participating in the sample. The first question asked: What can be the reasons for these learners' poor performance in these multiplication activities?

This question was asked during the analysis of three activities carried out by learners in the learner workbook. This is what teachers had to say:

Teacher A: "Mathematics is a difficult subject to those learners who are less gifted, as a teacher; I cannot create something that is not there."

Teacher B: "learners who experience difficulties are, those who are lazy to think and to reason even when you give them simple math problems to solve."

Teacher C: "CAPS learner books and teachers' guides provide activities that learners should do in the first term; therefore we steak to them." The second question was asked: Was your participation in baseline assessment activities of value to you as the mathematics teacher in grade four?

This question was asked to teachers after the activities.

Teacher A: "Yes, it was. It has been my view that not all learners are intelligent to grasp the knowledge of Mathematics, as the teacher of Mathematics in this over the years, some learners take time to differentiate between addition and multiplication."

Teacher B: "I am a new teacher, and I am teaching grade four for the first time. I learned from inclusive education that we should attend to individual learners learning barriers. I, also know about the theory of Gardiner. The problem, however, is that I did not have practical experience. This research has trained me in something of value. The challenge though, that our curriculum is restricted to learners' mathematics workbooks."

Teacher C: "I think, participating in this research was a golden opportunity for me. From this experience, I know that learners are judged unfairly by us, teachers. Honestly, I have not bothered about my slow learners. I will use this experience to continue to support my learners in the class."The third and the last question asked: Do you think are the advantages of considering different learning styles in the teaching and learning of Mathematics in grade 4?

The responses which we got from the teachers were the following: Teacher A: "The excitement and joy I witnessed in learners indicated to me that they loved what they were doing. I have also noticed that their participation and commitment to the activities improved"

Teacher B: "I have learned that over the years, I have been unfair in my judgment of learners, because due to my lack of knowledge about their learning 
styles, I concluded they have learning barriers and, there is no miracle to change those barriers. The heads of the department do not have a solution, and we subsequently promote them to the next grade with their barriers."

Teacher c: The mathematics learner workbooks do not provide activities based on these different learning styles. The assessment activities should not be the event of one size fits all." This thing of barriers and inclusivity and learner should be left behind; I consider this as just a slogan of the DBE. But what we have experienced worth it.

\section{Findings}

Results of baseline assessment expose diverse learning styles other than learning difficulties.

The traits and propensities presented in the bar chart, figure2, and andtable1 indicate a change in the learners 'performance, to the four criteria of the multiplication activities, respectively. The activities exposed learners to opportunities to master knowledge and skills of multiplication at their own pace and learning styles. The results highlighted the population of learners in the sample of 60 represented the demographics of the diverse learning styles in the bar chart, figure 2. The performance which could have been declared weak in the four aspects of multiplication appeared to have improved drastically.

Improvements in learners' performance highlight the importance and usefulness of baseline assessment in identifying the learning styles of learners in mathematics class. The analysis of the learners' performance provided informed the development of activities that accommodated diverse capabilities, interests, and frameworks for learning mathematics skills, knowledge, and logos.

The positive results obtained from a variety of activities confirmed assertions made by Kim (2019) and Tiymms (2013) that baseline assessment tasks provide adequate opportunities for learners to express their individuality in the learning process.

Planning and development of diverse activities offer learners opportunities to master multiplication skills at their level of cognitive processing.

Learners who met all four criteria were considered to have mastered multiplication set out in the learning outcome. This finding confirms Piaget's assertion that mastery of skills begins with the coding of concepts in the short term memory before proceeding to the working memory in the mind where meaning and understanding are accomplished Bondie et al. (2019). Such positive results endorse the principles of multi-level abilities teaching and multiple intelligences that learning of any knowledge and skills is determined by; flexibility of organization of material and familiarity with context (Tomlinson, 2020; Baubeng, Atingane \& Amoako, 2019).

This finding suggests strongly that the results of the baseline assessment are the performance indicators (PI) for differentiated learning (Tymms, 2013)

Findings were elucidated from data gathered from in-depth interviews with participating teachers.

The findings that emerged during the process of data analysis and its collection highlighted various issues about the learners and teachers participated in the sample. These issues were translated into themes for discussion. 
Theme 1: Inadequate theoretical and practical knowledge of baseline assessment The responses of the participants to the main question highlighted that their knowledge of baseline assessment did not resonate with the principles of inclusivity and differentiated learning advocated in the White Paper 6 (DBE, 2011). The responses of teacher, $A$, and $C$ to the question on the reasons for the high rate of failure in mathematics in the intermediate phase (middle classes) highlighted the lack of knowledge of the varying capabilities in the learning environment. This finding, therefore, answered the question asked in this article on how teachers in elementary mathematics classes identify differentiated learners' learning styles in mastering conceptual knowledge of multiplication and the application of numerical cognitive skills. The repeated mentioning of the Activities from textbooks as a means of baseline assessment indicated that participants were not certain about the rationale for conducting baseline assessment as part of implementing inclusive policy in teaching and learning.

Theme 2: Misconstrued understanding of differentiated learning styles versus learning difficulties

Analysis of responses highlighted that participants held the perception that differentiated learning styles refer to learning difficulties. The misconception of differentiated learning styles led other learners to state that they failed because they could not fit into the mainstream teaching and learning styles preferred by the teacher in the mathematics class; something highlighted in the utterance made by one participant: "learners who experience difficulties are those who are lazy to think and to reason even when you give them simple math problems to solve."

Theme 3: dependence on textbooks and curriculum guidelines for assessment activities.

The participants highlighted reliance on the prescribed learners' mathematics books and curriculum guidelines when conducting assessments. Textbook based activities in this argument are generic and are not suitable for implementing inclusivity in the mathematics classroom. The findings of this study confirm that teachers' creativity and flexibility could bring about fruitful intervention to promote equity and equal learning opportunities for all learners in the learning environment. The tendency of the Department of education to prescribe assessment tools for all learners in the grade is proven in this study to be an obstacle to teachers' critical and creative thinking about what their contextual reality demands. The study also, proved that teachers are capable of developing activities that suit their learners' experience and interests, and capabilities as well.

\section{Discussion}

This section discusses the synthesis of the findings of the research concerning the question, which was the main focus of the collection and analysis of data. The question sought to Is baseline assessment a reliable procedure to benchmark diverse learning needs in the elementary mathematics classes? 
The findings presented in this paper highlighted the possibility of improving the performance of learners in mathematics through careful planning and organizing activities driven by the abilities, needs, and interests of the learners. The findings of the research proved that baseline assessment activities provided diverse opportunities for learners to demonstrate their capabilities and interests. The activities were able to benchmark the interests, needs, and abilities which can guide further development of learning activities for the learners. According to Tomlinson (2020) baseline in the form of the formative assessment provide teachers feedback about the diverse needs and abilities to be considered when designing teaching and learning activities in the subject. The results of the study highlighted that, despite the argument of Henning et al. (2019 regarding the negative impact on the learning of mathematical content knowledge, the issue of pedagogical approach proved by this research to be the obstacle to learners with special learning techniques to demonstrate their capabilities.

The success in the improvement of underperforming learners scored through the baseline assessment activities confirmed the principle of a continuum in a performance highlighted by Armstrong (2009 p.146) that; flexibility in the organization of learning and assessment material and familiarity with the context are critical principles in differentiated learning styles. The evidence in Tables 1 and figure 2 proved that active involvement with objects engages learners in working with mathematical logos made learning of multiple of four practical and contextualized. Learners reckoned that logos are the mathematical language to communicate knowledge in different contexts. This finding was the realization of the idea that productive and meaningful learning of concepts and experience is possible in a framework that is familiar to learners.

The results and the findings presented in this paper highlight the value of baseline assessment to benchmark learning needs which prevail in mathematics class. The results of the baselines assessment were of assistant to teachers to develop mathematics teaching and learning activities in elementary classes. Teachers participating in the sample were eager to cooperate in learning about strategies of baseline assessment to identify distinct learning styles. The inability of mathematics teachers to develop baseline assessment activities was interpreted as a threat to inclusivity in learning, the result of which is the disadvantaging of other learners. The proposals and recommendations made on the grounds of this finding are two-fold: empowering mathematics teachers with strategies (i) to develop baseline activities and (ii) to analyze results according to learning styles.

\section{Limitations}

Even though, the fact that the findings shared in this article are of value and importance it is worth noting, however, that the sampling focused on three schools in a district with over 50 primary schools. The researcher could not access other schools due to time and financial constraints. 


\section{Conclusion and recommendation}

The analysis of the principles underpinning baseline assessment and the findings of this study, lead to the following conclusions about the process of benchmarking learners' approaches to acquiring mathematical knowledge. First, the principles of the theory of Multiple Intelligence which guided assisted this study to understand the implications of baseline assessment in practice. The principle of uniqueness of learners in the process of learning suggested by the advocates of differentiated learning techniques was confirmed by the results and the findings in the work (Dryden \& Vos, 2005; Bondie, Dahnke \& Zusho, 2019). Second, in addition to focusing on the reliability of the results, was that performance proved that teachers should reckon; flexibility in the organization of learning material contextualized learning of mathematics concepts, skills, and operation abilities, particularly for the intermediate phase (middle phase of school. Third, upon reflection, baselines activities appeared to be developing interest and positive attitude in learners toward mathematics. While acknowledging, the concerns of the rapid and radical curriculum change since 1997, and a lack of resources, and parental support highlighted by the Department of Basic Education (2019), Spaull \& Kotze (2015), the findings of this research, however, proved that consideration of differentiated learning techniques is lacking in mathematics teaching and learning, in some primary schools.

This study recommends that future studies could use the findings highlighted by this research to study, the application of baseline assessment to identify teaching techniques in mathematics classes on a larger scale and highlight other learning styles that are not part of this article. The study recommends the serious consideration of baseline assessment to be an essential aspect of a continuous professional program for mathematics teachers. Furthermore, the research highlighted that learners can reach their optimal levels in learning mathematics in a free and flexible environment. This paper concludes that the lack of knowledge about how to conduct baseline and its value is one of the serious attributes of the high failure rate of children in grade four. These findings highlighted in the article suggest that the department of education in South Africa should provide the teacher of mathematics in elementary classes with pedagogical content knowledge and training to handle issues of differentiated learning in mathematics class; this does not mean remedial teaching but an ability to develop activities to accommodate all styles of learning.

According to the findings of the research, the claim can be made that pedagogical strategies proposed for integrating teaching, learning, and assessment have not found their way into the practices of teachers in classrooms. Teachers in this study were seldom able to develop and plan learning and teaching activities sensitive to learners' diverse learning styles. The positive results indicate that baseline assessment could be of assistance to mathematics teachers to establish diverse learning styles in their classrooms; so that they can widen opportunities in their teaching of mathematics conceptual knowledge and algorithms. It was proven in the study that the principle of inclusivity in education promulgated by the Department of Basic Education (2011) in the 
White paper 6 regulations on inclusive education are not considered in the planning and organization of learning material, and subsequently, it is not implemented due to the lack of empowerment of mathematics teacher.

The first activity provided learners with the different settings to make their own choice and to count one cluster of objects in cycles and record the cycles of counting and the increase they observed in the rise in numbers.

This paper recognizes the demographics of diverse learning styles in mathematics classes, and the question was how the demographics contributed to the poor performance of learners in grade four in mathematics learning. The findings of the study indicated that learners', performance was focused on sound, weak and poor categories. The results presented in this work point to the inadequacies of mathematics teachers in the entry grade of intermediate phase to plan, and organize learning, and assessment activities to accommodate diverse learners' needs in mathematics classes.

The data and the findings presented in this article point out that a new and viable approach to teaching and learning of Mathematics knowledge and skills is necessary.

\section{References}

Aghamdi, A., Jitendra, A. K., \& Lein, A. E. (2019). Teaching students with mathematics disabilities to solve multiplication and division word problems: the role of schema-based instruction. Mathematics Education, 52(1), 125-137. https://doi.org/10.1007/s11858-019-01078-0

Amoako, I., Brembong, D. A., \& Bortey, J. (2019). Knowledge of Formative Assessment practices among senior High School Mathematics Teachers in Ghana. Open Journal of Social Science Research, 3(3), 8-13.

Andrade, H. L., \& Brookhart, S. M. (2019). Classroom assessment as the co-regulation of learning. Assessment in Education: Principles, Policy \& Practice, 27(4), 350-372. https://doi.org/10.1080/0969594X.2019.1571992

Baubeng, I. Atingane, A. B., \& Amoako. (2019). Practices, challenges, and Perceived Influence, of Classroom Assessment on Mathematics Instruction. International Journal of Assessment Tools in Education, 6(3), 476-486.

Blomeke, S., Kaiser, G., \& Koning, J. (2020). Profiles of mathematics teachers' competence and their relation to instructional quality. Mathematics Education, 52(2), 329-342. https://doi.org/10.1007/s11858-020-01128-y

Bondie, R, S., Dahnke, C., \& Zusho, A. (2019). How does changing "One Size Fits All" to differentiated Instruction Affect Teaching? Review of Research in Education (chapter 12, 43(1), pp. 336-362). SAGE Publication.

Davis, K., Christodoulou J. Seider, S., \& Gardiner H. (2011) The Theory of Multiple Intelligences. In R. J. Sternberg \& S. B. Kaufman (Eds.) Cambridge Handbook of Intelligence. Cambridge University Press: Cambridge.

Department of Basic Education. (2019). Mathematics Teaching and Learning Framework for South Africa: Teaching and Learning mathematics for understanding. Department Printers: Pretoria RSA.

Department of Higher Education. (2019). Minimum Requirement for Teacher Qualification in South Africa. Pretoria. Government Press.

Department of Basic Education. (2011) South African curriculum and assessment policy statements, Department of Education, Pretoria. 
Donohue, D. K., \& Bornman, J. (2014). The challenges of realizing Inclusive Education in South Africa, South African Journal of Education, 34(2),1-14.

Dryden, G., \&Vos, J. (2005) (Eds.). New learning Revolution. United Kingdom: Network Educational Press Ltd.

Fleisch, B. (2008). Primary education in crisis: Why South African schoolchildren underachieve in reading and mathematics. Juta, Cape Town.

Goulet-Lyle, M., Voyer, D., \& Wershaffel, L. (2019). How does imposing a step-by-step solution method impact students' approach to mathematics word problemsolving? Mathematics Education, 52(1), 139-149. https://doi.org/10.1007/s11858019-01098-w

Hazell, E., Spencer, G., \& Robert, N. (2019). Improving Grade R mathematics teaching in South Africa: Evidence from an impact evaluation of a province-wide intervention.

Henning, E., Ehlert, A., Balzer, L., Ragpot, L., Herholdt, R., \& Fritz, A. (2019) Marko-DSA: Assessment of number concept development. University of Johannesburg printers: Johannesburg RSA.

Henning, E., van Rensburg, W., \& Smit, B. (2013). Finding your way in qualitative research. Pretoria: Van Schaik

Kim, H. J. (2019). Teacher learning opportunities provided by implementing formative assessment lessons: Becoming responsive to student mathematical thinking. International Journal of Science and Mathematics Education, 17, 341-361.

Mullis, I. V. S., Martin, M. O., \& Hooper, M. (2017). Measuring changing educational context in a changing world: Evolution of TIMMS and PIRLS questionnaire. In M. Rosen, K. Y. Hansen \& U. Woff (Eds). Cognitive abilities and educational outcomes.

Nguare, M. W., Hungi, N., \& Mutisya, M. (2018). Assessing Learning: How can classroom-based teachers assess students' competences in Numeracy. Journal of Assessment in Education, 26(2), 222-244. https:// doi.org/10.1080/0969594X.2018.1503156

Reddy, V. B. (2006). Mathematics and science achievement at South African schools in TIMMS 2003. Cape Town.

Schollar, E. (2008). The primary mathematics research project 2004-2007: Towards evidencebased educational development in South Africa. Primary Mathematics Project, Johannesburg.

Semana, S., \& Santos, L. (2018) Self-regulation capacity of middle school students in mathematics. Mathematics Education, 50(6), 743-755. https://doi.org/10.1007/s11858-018-0954-0

Spaull, N., \& Kotze, J. (2015). 'Starting behind and staying behind in South Africa International Journal of Educational Development, 41, 13-24.

Tomlinson, C. A. (2020). Fulfilling the promise of the differentiated classroom: Strategies and tools for responsive teaching. Alexandria. Retrieved from http://www.ascd.org/publications

Tomlinson, C. A. \& Moon, T. (2013). Differentiation and classroom assessment. In J. H. McMillan (Ed.), SAGE handbook of research on classroom assessment (pp. 415-430). Los Angeles: SAGE.

Tymms, P. (2013). Baseline Assessment and Monitoring in Primary schools: Achievement, Attitudes, and Value-added indicators. New York: Routledge.

Veldhuis, M., \& van den Heuvel-Panhuizen, M. (2019). Supporting primary school teachers' classroom assessment in mathematics education: effects on student achievement. Mathematics Education Research Journal, 32, 449-471. https://doi.org/10.1007/s13394-019-00281-2 
Venkat, H., \& Spaull, N. (2015). What do we know about primary teachers' mathematical content knowledge in South Africa? An analysis of SACMEQ 2007. International Journal of Educational Development, 41, 121-130. https://doi.org/10.1016/j.ijedudev.2015.02.002

Wright, R. J. Martland, J., \& Stafford, A. K. (2006). Early numeracy: Assessment for teaching and intervention. London: Paul Chapman Publishing Ltd. 


\section{Appendix A: Activities of multiplication problems for baseline assessment}

\section{Activity One: multiples of two}

- Problem is counting objects in pairs or in the groupings of two, in a number of times and recording solutions or number patterns.

- Example:

Counting a pair

Once ( $1 \times 2$ objects)

Counting a pair twice ( 2 times $\times 2$ objects)

\section{Activity Two: Multiples of four}

- Problem is counting objects in the groupings of four

\begin{tabular}{|l|l|l|l|}
\hline Intelligences & $\begin{array}{l}\text { Techniques of solving } \\
\text { problems. Material chosen }\end{array}$ & skills & knowledge \\
\hline $\begin{array}{l}\text { Verbal Linguistic } \\
\text { Reading words and } \\
\text { listening }\end{array}$ & $\begin{array}{l}\text { Picture/ diagrams / } \\
\text { words }\end{array}$ & $\begin{array}{l}\text { Counting } \\
\text { Sorting } \\
\text { Organising } \\
\text { recognising }\end{array}$ & $\begin{array}{l}\text { Number } \\
\text { patterns } \\
\text { Concepts of } \\
\text { increase and } \\
\text { multiplication }\end{array}$ \\
\cline { 1 - 2 } $\begin{array}{l}\text { Bodily Kinaesthetic } \\
\text { Move around, } \\
\text { process information } \\
\text { through bodily } \\
\text { sensations }\end{array}$ & Games, role playing & & \\
\hline $\begin{array}{l}\text { Visual spatial } \\
\text { Imagine things, } \\
\text { working with visual } \\
\text { images and pictures }\end{array}$ & Pictures/ drawings & & \\
\cline { 2 - 3 } & & & \\
\hline
\end{tabular}

\section{Appendix B: Observation schedule}

\begin{tabular}{|l|l|l|l|}
\hline $\begin{array}{l}\text { Pseudonyms } \\
\text { for students }\end{array}$ & Interests & $\begin{array}{l}\text { Technique for solving } \\
\text { mathematics problems } \\
\text { (e.g. games, drawing) }\end{array}$ & Performance \\
\hline Learner R & & & \\
\hline Learner V & & & \\
\hline Learner M & & & \\
\hline Learner P & & & \\
\hline
\end{tabular}




\section{Appendix C: in-depth interview questions}

(i) How do you assist learners who are not performing well in your mathematics class?

(ii) What can be the reasons for these learners' poor performance in these multiplication activities

(iii) Was your participation in baseline assessment activities of value to you as the mathematics teacher in grade four?

(iv) Do you think are the advantages of considering different learning styles in the teaching and learning of Mathematics in grade 4 ? 